Available online at http://jgu.garmian.edu.krd

Journal of University of Garmian

https://doi.org/10.24271/garmian.1964028

\title{
A comparison between representing word meanings in two advanced learner's dictionaries
}

\author{
Sara Jamal Mohammed
}

Department of English language, Faculty of Education, Koya University

\section{Article Info}

Received: Novemebr, 2019

Revised: December, 2019

Accepted: December, 2019

\section{Keywords}

Macmillan, Cambridge, dictionary, word meaning, representing, advanced learners

\section{Corresponding Author} sara.jamal@koy auniversity.org

\begin{abstract}
Human beings can communicate through utilizing various types of languages in the world. However those languages are internationally or locally used by utterances. Undoubtedly, different types of dictionaries are available in English language as a global language in order to support second language learners in realizing word meanings. In this study two different types of advanced learner's dictionaries are highlighted regarding to the way of expressing or representing word meanings, which are Macmillan and Cambridge advanced learner's dictionaries. The objective of this study is try ing to recognize if there is any difference between these two dictionaries in demonstrating word meanings. Selecting as the most effective one for advanced learners can be count as the second aim of this study. The methodology in this study is purely theoretical. Different features are selected for investigation in both elected dictionaries, such as providing common words, phonetic transcription of the headwords by phonetic symbols. Moreover, the result show that the Macmillan Dictionary provides effective definitions for advanced learners because it lays out the meanings of simple and common words at the same time. Drawing pictures or just by making sketch are the other two ways that followed by both dictionaries and makes word meanings more clear.
\end{abstract}

\section{Introduction}

There are a great number of languages in the world that have been used by human beings. Most of the global languages have a particular dictionary in order to support foreign learners in learning the language as a second language. A dictionary can be defined as a reference book which includes thousands of different words and phrases with definitions and extra information that is ordered alphabetically. There are different types of dictionaries which are available and for different levels of learners. Advanced learner's dictionaries, such as the Macmillan and Cambridge dictionaries, which are produced for non-native speakers, enable learners to feel confident when they refer to each kind of advanced learner's dictionary. Hacken (2009: 415) argued that dictionaries do not explain the whole language but they do provide information about the words. Therefore, with this information many questions can probably be answered. Learners try to solve many problems by consulting dictionaries. Moreover, advanced learner's dictionaries share the same features that make them unique. The meanings of common words are fundamentally recorded in advanced learner's dictionaries. Distinguishing between the head words, 
according to parts of speech, is important because sometimes the meanings of the words can be changed when the words act as nouns, verbs, adjectives or adverbs. Another feature is that they provide a phonological transcription of the word by using phonetic symbols. Finally, they represent various meanings of headwords in clear and accurate definitions, which is another crucial feature of advanced learner's dictionaries. However, there are reasonable numbers of similarities in indicating word meanings which can be determined between the Macmillan and Cambridge dictionaries, but there are also differences. For example, some headwords have many different senses that reach to more than five entries; whereas the Macmillan Dictionary covers a menu of short phrases for those words. At the same time, the Cambridge Advanced Learner's Dictionary refers to different meanings for the same word by using small boxes with different single words besides each headword. In addition, the Macmillan Dictionary indicates the most general meanings of words at the beginning, and then explains the other meanings for different purposes. Because both selected dictionaries exemplify meanings by sentences, this makes it easier for the advanced learner to understand the meaning of the word, as well as the usage of the word in context. In fact, the use of common vocabulary items are more focused by lexicographers for definitions in the Macmillan and Cambridge dictionaries for advanced learners because these common and simple words are more familiar to second language learners. Thumb (2004: 273) noticed that different strategies have been practiced by learners for realizing new meanings, while reading texts in English, to improve their knowledge of vocabularies. Ignoring and checking are two types of strategies which are used by learners. When learners are looking up a specific meaning but, having found the right word meaning they can ignore it and search for other, this means that they want to know more about the selected word. Also, a checking strategy is making a comparison between different meanings of the same headword. Furthermore, pointing out meanings of words by drawing pictures is influential, when abstract lexica's are introduced by pictures, meaning definitions and sentence illustrations are not necessary, this obviously is very effective and interesting. This essay will examine how different meanings of words have been represented in advanced learner's dictionaries, especially the Macmillan and Cambridge Advanced Learner's Dictionaries. This paper will also focus on the comparison and similarities between these two dictionaries in the definitions of the words. The strong and weak points in representing meanings of headwords in the Macmillan and Cambridge dictionaries have been investigated in this essay.

\section{Hypothesis of the study}

It is quite clear that large numbers of previous authors had underlined the importance of producing various types of languages especially English language as a global language. Also, advanced second language learners can hardly ever feel confident in selecting effective dictionary that provides word meanings with clear definition.

\section{The scope of the study}

This paper in mainly aimed to deal with representing word meanings and explanations in two different types of advanced learner's dictionaries. And evaluating both selected Macmillan and Cambridge advanced learner's dictionaries in means of most of the words features.

\section{The purpose of the study}

The major purpose of the study is to examine the most effective way of representing word meaning and definition in both Macmillan and Cambridge advanced learner's dictionaries. Also, indicating word details of single words in order to make a distinction between both selected dictionaries for the second language learners. However, it will be a quick process while Kurdish women and men use devices for performing word meaning but may be they physically harmed. This study selected the two main dictionaries that mostly used by English language learners.

\section{Background of the study}

There are many different types of dictionaries which are available for various levels, but the more comprehensive and effective ones are those that are produced to fulfil advanced learners' demands. These 
learners, who are not normally English language speakers, use these dictionaries which are specialized for their level. Complex and rare words are the two particular groups of words that are highlighted in advanced learner's dictionaries. Certainly, the Macmillan English Dictionary is one of the types of dictionaries which have compiled a huge number of words for high-level learners and this is another feature of this dictionary. The numbers of words that are collected in the Macmillan English Dictionary is nearly 2,500. This means that advanced learners could probably reach their main aims of understanding when they try to find out complex or difficult words for different purposes during their study. The same feature can be found in the Cambridge Advanced Learner's Dictionary, which covers numerous words, up to 3700 , which are more words than the Macmillan Dictionary. Moreover, the Macmillan and Cambridge Advanced Learner's Dictionaries cover most of the commonly used English words. A good illustration for this is the word library which refers to 'a public place where books, documents, CDs and many other sources of information are provided for you to read, listen or borrow', this word is in both of the dictionaries and has the same meaning. Kern (2005: 4) noticed that the dictionaries of advanced learners are used for multi purposes because common words make a strong connection among non-unique mother-tongue speakers or speakers with using different languages. Bogaards (1996: 229) argued that the English language will never become a foreign learner's first language, even if they reach to the highest level, they will remain learners, but at different levels. Therefore, the dictionaries that have been published for advanced learners can serve all their learning necessities. Therefore, advanced learner's dictionaries have contained terms from academic books and scientific documents in order to make learners feel more familiar with these complex words. Herbst (1988: 385) explained that most of the recorded words in advanced learner's dictionaries are followed by phonetic descriptions of the words in order to increase a learner's knowledge about word pronunciations. Therefore, the Cambridge Advanced Learner's Dictionary is one of the dictionaries that include the pronunciation of the words by using phonetic symbols. For instance, /dzo'netık/ is the transcription of the word genetic, which is "the term related to genes and investigating of them". Similarly, the same features can be seen in the Cambridge Advanced Learner's Dictionary, for example, /dzo'netik/ is also the transcription of the same word.

Moreover, Mohammed (2013) asserted that providing grammatical information in advanced learner's dictionaries is one of the basic properties that support learners to make a distinction between a learner's dictionary and other ordinary dictionaries. Parts of speech are one of the basic parts of grammar and they are available in these types of dictionaries because they help learners to understand the meanings of the words easily and quickly. Therefore, the words' parts of speech are located besides the most of the lexemes or words in the learner's dictionaries, because word meanings can change depending on the types of parts of speech. For example, the meaning of the word effect in the Macmillan English Dictionary is "a change that is produced in one person or thing by another', when it is a noun. However, the meaning of the same word effect is partially changed when it works as a verb, which is "to make something happen". Furthermore, both structure and the meaning of the selected word is changed to effective and the meaning is "someone or something that is effective works well and produces the result that was intended", when it behaves as an adjective. It is interesting to mention that the same feature can be found in the Cambridge Advanced Learner's Dictionary, which is that parts of speech of the same word effect are changed and it causes word meanings to change as well. So, the Cambridge Advanced Learner's Dictionary shows the meaning of the word effect when it is a noun, as: "the result of a particular influence". When it changes to an adjective, the word is changed to effective and the new meaning is: "successful or achieving the results that you want". The difference between these two types of advanced learner's dictionaries becomes clearer in representing the meaning of the words. In the Macmillan Dictionary, the meaning of the word effect is expressed by explaining and defining it briefly and clearly and it does not use the headword itself in the explanation, which makes the meaning more understandable. Whereas, in the Cambridge Advanced Learner's Dictionary, the meaning of the word is represented by using other words or it could be said the meaning is paraphrased, but it is somehow 
complicated when compared with the Macmillan Dictionary. For instance, the phrase" particular influence" is used for expressing the meaning of the word effect in the Cambridge Advanced Learner's Dictionary, which is not clear about the type of influence. However, in the Macmillan Dictionary it is explained by pointing out "the change will happen by a person or something", so the learner can manage to understand the meaning and usage of the selected word simply in their speaking or writing.

It is interesting to mention that word definitions can be counted as the most important field in all kinds of learner's dictionaries because learners are mainly searching in dictionaries to find effective meanings. Hornby (1975: 78) noticed that definitions are pointed out differently in various types of dictionaries, and advanced learning dictionaries are one of these kinds of dictionaries. Certainly, providing meaningful definitions in dictionaries, which are used by foreign advanced learners, will support learners to know how the English words are used correctly in contextual usage or in speaking skills. The Macmillan and Cambridge Advanced Learner's Dictionaries both define the words with illustrations but in different structures. To illustrate, the word business is defined in both of the selected dictionaries for advanced learners, but they are not similar in their representation. A brief meaning is given under the headword, in order to help the reader to find the specific meaning of the word that they are looking for. The Macmillan Dictionary presents five meanings in a menu for the word business, which are: "buying and selling, organization, something to deal with, of one particular person, event". These are explained in detail with each specific phrase that is mentioned in the table briefly coming after the menu with exemplifying sentences. For instance, a sentence for the first phrase is "I found them very easy to do business with". The Macmillan Dictionary explains each phrase separately in detail, which is different from the Cambridge Advanced Learner's Dictionary in some situations. A good illustration for that is the full explanation of the first phrase: "buying and selling" is "the work of buying or selling products or services for money".

On the other hand, the Cambridge Advanced Learner's Dictionary starts with giving the explanations of the headword, without representing any types of menu for headwords and provides examples for each of the different meanings, one by one. For example, the first explanation of the word business is: "the activity of buying and selling goods and services, or a particular company that does this, or work you do to earn money". Perhaps the different words that are used by the Macmillan Dictionary and the Cambridge Advanced Learner's Dictionary are differentiated by structural differences, which make the reader spend more time in finding the accurate meaning of the word. For instance, the Macmillan Dictionary mentions that business is a kind of work that relates chiefly to "money" but in the Cambridge Advanced Learner's Dictionary it mentions that it is "work for services". The Macmillan Dictionary covers five different meanings for the word business as a noun, but just three different meanings are given in the Cambridge Advanced Learner's Dictionary so the other two are: "a situation or activity, often one that you are giving your opinion about"; "the things that you are do or the matters which relate only to you".

However, there are other common words, which are recorded in both the selected dictionaries for advanced learners, which are mostly like each other in definition. For instance, the word suffer refers to "feeling pain in body or mind" and the exact explanation in the Macmillan Dictionary is:"to feel pain in your body or your mind". Moreover, Harmer (2002: 423) noticed that the Macmillan Dictionary for advanced learners is significant among other dictionaries because of its giving easy and clear guidance to various meanings and excellent notice about word usages. Definitions of words with examples are represented carefully in the Macmillan Dictionary. Also, nearly the same definition structure can be found in the Cambridge Advanced Learner's Dictionary, which is: "to experience physical or mental pain". Therefore, both types of dictionaries have the same definition for the word suffer, which is mostly related to pain, whenever it is a body ache or mental pain. Also, the Macmillan and Cambridge dictionaries have given meaningful sentences as examples for the word suffer to show where it should be located in sentences. For instance, the sentence that is given in the Macmillan Dictionary is: "Patients suffering from Alzheimer's disease". Furthermore, the example, which can be found in the Cambridge Advanced Learner's Dictionary, is: "She has been suffering from cancer for two years". It is clear that 
when both dictionaries try to deal with the word "pain" they use suffer to show that how it should be used by learners when they want to practice this word correctly.

Moreover, the Macmillan Dictionary provides the meaning of some particular words in general, and then offers different meanings of the same word, which are used in various situations with examples of meaningful sentences. The Cambridge Advanced Learner's Dictionary tries to represent the most common meanings which are used by English speakers, besides the meaning of the word in general. This difference can be seen in the common word shake, which is available in both dictionaries. The Macmillan Dictionary defines the word shake firstly, when it works as a verb, as "to make lots of quick small movements up and down, or side to side", so it talks about the verb shake generally at the beginning in order to give a brief idea to the reader about the meaning and to explain the different directional movements. However, the Cambridge Advanced Learner's Dictionary indicates the meaning of the word shake as a verb, which is:"to move backwards and forwards or up and down in quick, short movements, or to make something or someone to do this". There is no doubt about it that the Cambridge Advanced Learner's Dictionary refers to the meaning of the word shake like the Macmillan Dictionary in general, but it does not mention the different directional movement, 'side to side', which is another kind of movement that produces a shaking action.

Another crucial and beneficial demonstrating function of the Cambridge Advanced Learner's Dictionary is its representation of the brain storming idea about the meaning of the word in a small box next to the headword. The prominence of having different word guides in small boxes for the same headword makes the reader realize the numbers of different meanings. Normally, readers try to find out different meanings of the headwords before looking at the detail of each of the different meanings and sentence examples as well. For illustration, let us look at the word set, which is counted as one of the words that has various meanings and is used for different purposes. In the Cambridge Advanced Learner's Dictionary these different meanings are recorded as "position, condition, establish, group, get ready, fix, part", so the reader can manage to understand numerous meanings, which are completely different from each other in a short space of time. In addition, when the word set is combined with prepositions, or other words, many new meanings and usages will be proposed. For example, the word sunset is produced by linking two meaningful words together, such as sun and set. When these words are used individually they have a particular meaning but when they act as a compound word it refers to a quite different meaning. The Macmillan Advanced Learner's Dictionary is designed to have a menu (as mentioned above) that includes different meanings given by phrases under the headword, and then points out definitions for each phrase in detail. Rundell (2004: 302) explained that defining the meanings of headwords in the Macmillan Dictionary by short phrases in a menu is worthwhile because that menu prevents the reader from losing time by searching for a meaning. For instance, the same lexical word set that functioned as a verb has many different meanings, which are to "put somebody or something somewhere, make something happen, make equipment ready, decide time/place/value, establish a way to do something, do something that influences, give somebody something to do, put a story in a time/place, when the sun goes down, position of broken bone, liquid becomes solid, have a fixed expression, arrange wet hair, arrange letters to print, put jewels in jewellery". It is interesting to mention that the representation of meanings of the words by phrases in the Macmillan Dictionary has its own advantage, which is to make the learner achieve an understanding of different meanings of the word in phrases. For example, in the sentence:"you will never get anywhere if you don't set yourself any goals", it shows the use of the verb set which means 'to give something to somebody to do it or achieve'. So, when the meaning is explained by phrases, then exemplified by a full sentence, the learner will be more familiar with the meaning and usage of the particular word.

Despite the differences that are highlighted above, there are similarities that can be realized between the Macmillan and Cambridge Dictionaries for advanced learners because both are used by the same level of learners. Indicating meaningful definitions or explanations for the headwords are provided in both of the two selected dictionaries, rather than involving the guide words and short phrases to give brief ideas to the learners. For example, the lexical word patient 
means "a person who is receiving medical care", therefore, the meaningful definition which is given in the Macmillan and Cambridge dictionaries is the same, without showing the meaning of the word by phrases, or just by one word, as it is in the Cambridge Dictionary. In addition, sentence examples are available in the Macmillan Dictionary for improving the knowledge of advanced learners about how the selected word is used in context. There are different sentences which are available as an example for the same word. A good illustration for this are the sentences: "our goal is to provide a good standard of medical care" and "Paul scored three goals in the game". The sentence that is produced indicates where the word goal should be located, when it is used in a context in order to give the right meaning of the word. The first sentence makes the reader realize the correct use of the noun goal when it acts to refer to the 'aim', and in the second sentence, the word goal is used to illustrate an action in sport. By the same token, the Cambridge Advanced Learner's Dictionary provides sentences for the same headword goal, which are used for the same purpose as it is used in the Macmillan Dictionary "our goal is for the country to be fully independent within two years", so the word goal is used in that sentence where it means 'aim'. However, in the sentence: "Brazil won by three goals to one" the same lexical word goal states a sporting action.

Interestingly, defining meanings of the words by using these vocabularies that are controlled and which are familiar to advanced learners is vital because these kinds of definitions attract the reader's attention. Similarly, the Macmillan and Cambridge Advanced Learner's Dictionaries have the same structure in defining the meanings of the headwords by using simple and controlled vocabularies at the same time. Furthermore, Cowei (1999: 156) explained that foreign learners normally take particular care in their choice of vocabularies because these learners are trying to improve their knowledge about vocabularies through use of those dictionaries that are designed for their level. Obviously, including ambiguous or unfamiliar terms in definitions in dictionaries takes the reader in the opposite direction in order to understand the right meaning of the word. Moreover, Aarts (1991: 217) argued that sometimes the definitions of the headwords in advanced learner's dictionaries are so clear and direct that they do not need to be explained by further sentences. For instance, the Macmillan English Dictionary highlights the first main meaning of the word honey as: "a sweet, sticky yellow or brown food made by bees" without providing any sentences as an example. Therefore, the meaning of the word honey is clear because the meaning has been explained exactly by using the word 'sweet', which is the most important word for defining the lexical word honey, also it used 'food' and 'bees', which are the other two crucial words that will lead the reader in the right direction. Furthermore, the term honey is also defined in the Cambridge Advanced Learner's Dictionary as: "a sweet sticky yellow substance made by bees and used as food". However, the definition of the word honey is reworded in the Cambridge Dictionary but there are also no sentences available as examples.

There is another way of representing the meaning of words, which can be seen in both dictionaries, which is drawing pictures or outlining different shapes. The function of having these pictures is to send the message to the learners without confusion. In addition, Stein (1991: 99) mentioned that the role of the senses and definitions are always preeminent in various types of dictionaries that are also supported by illustrations. Despite recording numerous sentences for examples, pictures are also provided in dictionaries for advanced learners in order to explain complex denotations. A collection of single or groups of colourful pictures can be noticed in advanced learner's dictionaries in a separate part in the dictionary, which makes the dictionary more unique. And there is no doubt that, through these drawings, the transmission of knowledge is achieved successfully and this helps to build learners' interest in them at the same time when they are searching for meanings for words. For example, a box of different pictures is produced for indicating the different meanings of the word filter because more than one type of filter is available and used in daily life, so besides each type of filter a particular picture is drawn to refer to the exact meaning. Moreover, different types of colourful pictures are available for different purposes, for instance, there are many sorts of hairstyles and hats which are provided in the Cambridge Dictionary that support the learner's ability to manage the meaning of the words without dealing with the meaning in detail. Words, such as 'curly, flat, spiky, cornrows, wavy' that represent hair 
styles and 'cap, top hat, turban, bonnet, trilby' and many other meanings are used to refer to hats.

As a consequence, depending on the numerous differences and similarities that have been pointed out between the Macmillan and Cambridge Advanced Learner's Dictionaries in representing the meanings of words, both of the selected dictionaries have advantages and drawbacks. There are valuable functions of representing word definitions that are available in the Macmillan Dictionary, which enable advanced learners to increase their knowledge in recognizing the accurate meanings of the words. Firstly, the menu that is provided under each headword and covers short phrases about different meanings of the headwords, supports learners to find out about various meanings of the selected words in a short time period. Secondly, it uses simple and common words at the same time, when it refers to the meaning of the word in detail. In addition, it deals with the more general meanings of the words in society, then moves to explaining each different word specifically, which is another important feature of the Macmillan English Dictionary. Likewise, the Cambridge Advanced Learner's Dictionary demonstrates the meaning of headwords in quite clear definitions, which is vital for advanced learners. Describing different meanings of the words by guidewords in boxes with small font sizes gives the learner brain storming ideas about the meanings of the word which also saves the reader time. Advanced learners can get more benefit from the explanations of meanings by phrases than just by single words in a short time as well because it is clear that meanings become more understandable. The Macmillan Dictionary deals firstly with the general meanings of the headwords, then mentions other particular definitions, but this feature cannot be seen in the Cambridge Dictionary. Advanced learners can manage to use the headword in context because sentences are provided as examples to make the learner's understanding clear about using words in context. The difference is quite narrow between the Macmillan and Cambridge dictionaries because both are published specially for advanced learners and they share similar features. However, depending on these differences and similarities outlined above, most of advanced learners can reach their learning goals by keeping the Macmillan Dictionary as their model to refer to so as to get a better outcome for their learning aims.

\section{Statement of the problem}

To underline this is sue, the study aimed to answer the following research questions depending on the research literature. The questions are clearly highlighted below:

1- Are both Macmillan and Cambridge advanced learner's dictionaries differ from each other in representing word meaning?

2- What are the word features that have been focused on, which occur in both selected dictionaries?

3- What is the most effective dictionary that supports advanced learners to feel confident in finding clear word definition?

\section{Evaluating, result and discussion}

To sum up, the Macmillan and Cambridge dictionaries are counted as two useful dictionaries for advanced learners. There are some general features which occur in both that have been focused on by advanced learner's dictionaries in general, such as: providing common words, phonetic transcription of the headwords by phonetic symbols, referring to the word meanings depending on the parts of speech of the words, definitions in different structures and many other features. Both of these dictionaries provide various definitions of the words, which is the most important part for dictionaries. The Macmillan Dictionary presents the meaning of the headwords in a menu and includes several short phrases underneath most of the words to support the learners to discover different meanings. Whereas the Cambridge Advanced Learner's Dictionary demonstrates various meanings of the headwords by single lexical words in small boxes beside each headword. It can be said that the Macmillan Dictionary provides effective definitions for advanced learners because it lays out the meanings of simple and common words at the same time. The valuable and interesting point in both the Macmillan and Cambridge dictionaries is the representation of the word by drawing pictures, or just by a simple sketch, which makes the meaning of the word clearer, even without sentence examples. This is, therefore, is beneficial for learning word meanings accurately. Hence, the implication of this study is obvious instructors and second language 
learners satisfied with realizing lexical meanings, pronunciations and grammatical forms for the unknown words.

\section{References}

1. Aarts, F., 1991.OALD, LDOCE and COBUILD.Three Learner's Dictionaries of English Compared in Perspectives on the English Lexicon.Cahiers de l'Institut de linguistique de Louvain. 17(1), pp. 211-226.

2. Bogaards, P., 1996. Dictionaries of learners of English.International Journal of lexicography. 9 (4), pp. 227-320.

3. Cambridge learner's dictionary. Available from: http://dictionary.cambridge.org/dictionary/learnerenglish/ [Accessed 19 April 2013].

4. Cowei, A.P., 1999.English dictionaries for foreign learners: A history. United States of America. Cambridge University Press.

5. Hacken, P.T., 2009. A view from Chomskyan linguistics.International journal of lexicography. 22(4), pp. 399-421.

6. Harmer, J., 2002.Macmillan English dictionary for advanced learners.ELT Journal. 56(4) , pp. 421423.

7. Herbst, T., 1988. Reviews: Collins COUBILD English dictionary. System. 16 (3), pp. 384-388.

8. Hornby, A.S., 1975. Oxford advanced learner's dictionary of current English. Teachers of English to speakers of other languages, Inc.(TESOL). 9 (1), pp. 77-79.
9. Kern, C., 2005. Learner's dictionaries of English.An overview. Germany: University of Bayreuth. Available from: http://books.google.co.uk/books ?hl=en \&lr=\&id=rct 2B4qfccIC\&oi=fnd $\& p g=P A 3 \& d q=$ definitions + styl e+in+advanced+learner $\% 27 \mathrm{~s}+$ dictionary \&ots =tdQs $4 \mathrm{kEaSe} \&$ sig $=\mathrm{eNV} 12 \mathrm{hjMgWdrkFuTp} 17 \mathrm{HzrFNAkg}$ $\# \mathrm{v}=$ onepage $\& \mathrm{q}=$ definitions $\% 20$ style $\% 20 \mathrm{in} \% 20 \mathrm{adv}$ anced $\%$ 20learner's \%20dictionary $\& \mathrm{f}=$ false [Accessed 7 April 2013].

10. Macmillan dictionary online. Available from: http://www.macmillandictionary.com/ [Accessed 27 April 2013].

11. Rundell, M., 2004.Macmillan essential dictionary for learners of English.Oxford journals search. 58(3), pp. 301-304.

12. Rundell, M., ed. 2007. Macmillan English dictionary for advanced learners. 2nd Edition. Oxford: Macmillan Education.

13. Stein, G., 1991. Illustration in dictionaries.International journal of lexicography. 4(2), pp. 99-127.

14. Thumb, J., 2004. Review: Dictionary look-up strategies and the bilingualised learner's dictionary. International journal of lexicography. 18(2), pp. 272-274.

15. Walter, E., ed. 2005. Cambridge advanced learner's dictionary. 2nd Edition. Cambridge. Cambridge University Press. 